\title{
Bridging Capillary-Driven Fragmentation and Grain Transport with Mixed Columnar-Equiaxed Solidification
}

\author{
CHRISTIAN M.G. RODRIGUES, MENGHUAI WU, HAIJIE ZHANG, \\ ANDREAS LUDWIG, and ABDELLAH KHARICHA
}

\begin{abstract}
In this study, a first attempt is made to bridge capillary-driven fragmentation and grain transport using a mixed columnar-equiaxed solidification model. Grain transport is an intrinsic feature of the employed solidification model which has been extensively investigated over the years. Regarding the capillary-driven fragmentation event, a new correlation between the number of fragments and interfacial area density of the columnar structure was recently established by Cool and Voorhees (2017) based on experimental research under isothermal conditions. Here, we propose to modify Cool and Voorhees' equation to extend its range of applicability to the solidification-dominant stage without destroying the agreement with the reported measurements in the coarsening-dominant stage. With this improvement in the mixed columnar-equiaxed solidification model, capillary effects can be isolated from the motion of the phases during fragmentation events, which facilitates understanding of the results. Under pure diffusive solidification conditions (no flow or crystal sedimentation), the simulation results were validated against phase-field simulations. In more realistic scenarios where liquid flow and fragment sedimentation are both considered, the simulations indicate very reasonable results for the detection of columnar-to-equiaxed transition, which suggests that the newly proposed model can be an important tool for industrial casting applications. Moreover, flow direction and intensity were shown to affect the potential for local fragmentation.
\end{abstract}
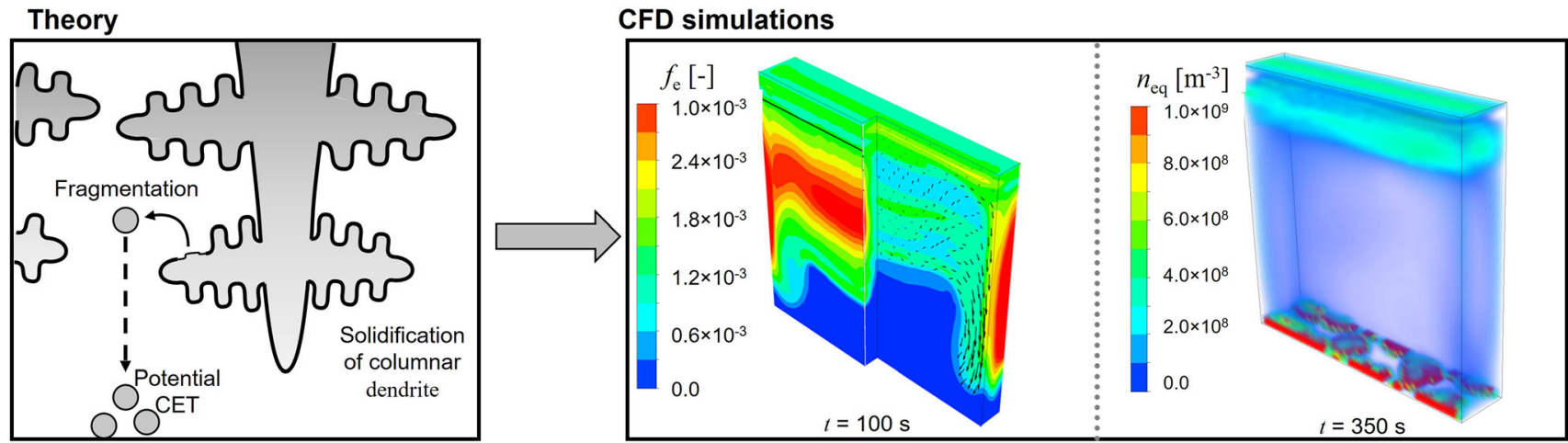

https://doi.org/10.1007/s11661-021-06414-2

(C) The Author(s) 2021

CHRISTIAN M. G. RODRIGUES, MENGHUAI WU, HAIJIE ZHANG, ANDREAS LUDWIG are with the Metallurgy Department, Chair of simulation and modeling metallurgical processes, Montanuniversity of Leoben, Franz-Josef Street 18, 8700 Leoben, Austria. Contact E-mail: menghuai.wu@unileoben.ac.at ABDELLAH KHARICHA are with the Metallurgy Department, Montanuniversity of Leoben and also with the Christian-Doppler Laboratory for Metallurgical Application of Magnetohydrodynamics, Montanuniversity of Leoben, Franz-Josef Street 18, 8700 Leoben, Austria.

Manuscript submitted on April 20, 2021; accepted July 25, 2021.

Article published online August 12, 2021

\section{INTRODUCTION}

DENDRITE fragmentation is a well-known solidification phenomenon that influences the formation of as-solidified microstructures. For instance, dendrite fragments, which are naturally produced during solidification and coarsening, may be transported out of the columnar mushy zone into the bulk melt region and survive the superheat. If they continue to grow into equiaxed dendrites, they can lead to a structural 
transition called columnar-to-equiaxed transition (CET) ${ }^{[1]}$ Despite its technological significance, controlling such a microstructural transition has not been established in the industry. A comprehensive understanding of dendrite fragmentation and its coupling with multiphase transport phenomena is still to be achieved.

\section{A. Capillary-Driven Fragmentation}

Although mechanical fracture due to natural or forced flow was initially assumed as the direct cause of dendrite fragmentation, ${ }^{[2]}$ it is now widely accepted that fragmentation originates from remelting of the roots of dendrite arms during coarsening. ${ }^{[3-5]}$

Coarsening refers to capillary-driven and diffusion-governed mass transfer caused by irregular solid-liquid interfacial curvatures. Transport of solute/solvent in the liquid leads to the growth of solid dendrites in regions of lower curvature at the expense of regions of higher curvature. Contrary to solidification, the slower coarsening process tends to reduce the number of side branches and the total interfacial area of the solid dendritic structure. ${ }^{[6]}$ This means that solidification and coarsening have opposing effects on the network morphological evolution, even though the capillary-driven mechanism is typically dominant at a later stage during casting. ${ }^{[7]}$

Based on experimental observations of the dendritic side-branch evolution of a succinonitrile model alloy, ${ }^{[8]}$ three distinct morphological changes have been identified during coarsening ${ }^{[7]}$ (illustrated in Figure 1): (a) retraction or complete remelting of the small side branches toward their parent stem when coarsening is dominant over dendritic growth and remelting of the tip takes less energy than that of the root; (b) coalescence of neighboring branches when the cooling rates and solid fraction are high and the space between the side branches is small, i.e., lateral growth is faster than the capillary-driven mechanism; and (c) fragmentation of the side branches when the remelting of side-branch roots requires less energy than the full retraction of the side branches and dendritic growth is not sufficient to promote coalescence. The outcome of the above

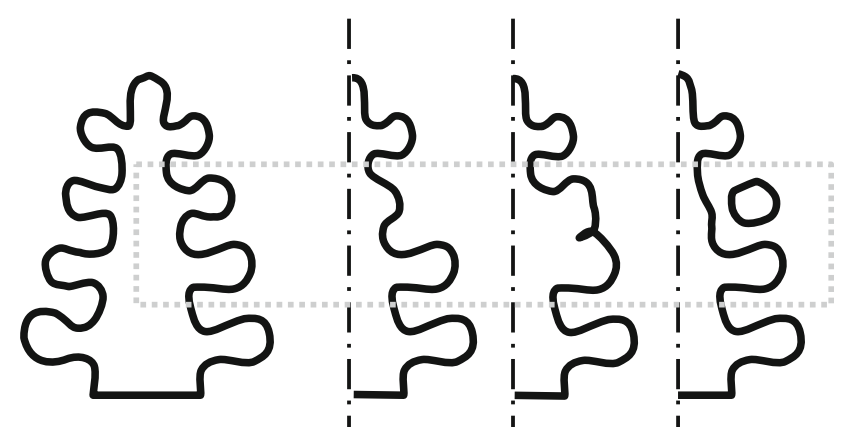

(a)

(b)

(c)

Fig. 1-Schematic diagram of the three distinct morphological changes in dendritic structure during coarsening: (a) retraction, $(b)$ coalescence, and $(c)$ fragmentation. scenarios depends strongly on the initial dendrite arm length, spacing, and orientation. ${ }^{[7,9]}$

A recent microgravity solidification/coarsening experiment aboard the International Space Station found that the number of fragments per unit volume $\left(N_{\mathrm{V}}\right)$ produced during isothermal coarsening can be described as a cubic function of the specific surface area $\left(S_{\mathrm{S}}\right)$ of the dendrites. ${ }^{[10]}$ On this basis, the production rate of fragments $\dot{N}_{\mathrm{V}}$ can be derived as follows:

$$
\dot{N}_{\mathrm{V}} \equiv \frac{\mathrm{d} N_{\mathrm{V}}}{\mathrm{d} t}=\frac{\mathrm{d}\left(a \cdot S_{\mathrm{S}}^{3}\right)}{\mathrm{d} t},
$$

where $a$ is an alloy-dependent constant, which is equal to $0.5 \times 10^{-4}$ for $\mathrm{Pb}-\mathrm{Sn}$ alloy. The specific surface area $S_{\mathrm{S}}$ is a quantity for characterizing the morphology of dendrites, and it is defined by the total interfacial area per volume of the enclosed solid phase. Another option is the interfacial area density $S_{\mathrm{V}}$, which is defined as the total interfacial area per volume of the solid-liquid mixture, i.e., $S_{\mathrm{V}}=f_{\mathrm{s}} S_{\mathrm{S}}$. Both $S_{\mathrm{S}}$ and $S_{\mathrm{V}}$ provide an accurate length scale of the structure, which is independent of its morphology. Note that the symbols used to represent these two quantities are sometimes inverted in some literature sources.

According to the classical coarsening law, ${ }^{[1]}$

$$
S_{\mathrm{S}}=\left(S_{\mathrm{s} 0}^{-3}+K_{0} t_{\mathrm{s}}\right)^{-1 / 3},
$$

where $S_{\mathrm{s} 0}$ and $K_{0}$ are alloy-dependent fitting constants, and $t_{\mathrm{s}}$ (local solidification time) is the time from the first appearance of the local columnar structure. It is worth highlighting that experimental studies ${ }^{[12-14]}$ have suggested that, under forced flow conditions, a better fit for the exponent in Eq. [2] would be achieved by the value of $-1 / 2$ instead of $-1 / 3$.

From Eq. [2], it is evident that the capillary-driven and diffusion-governed coarsening process leads to a decrease in $S_{\mathrm{S}}$ as $t_{\mathrm{s}}$ increases. However, note that Eq. [2] is not suitable when the solid volume fraction increases rapidly through the dendritic growth. Recently, Neumann-Heyme et al. ${ }^{[15]}$ proposed a time-dependent expression that covers the entire casting spectrum:

$$
S_{\mathrm{S}}=\left(1-f_{s}\right)^{\mathrm{r}}\left(S_{\mathrm{s} 0}^{-3}+K_{0} t_{\mathrm{s}}\right)^{-1 / 3} .
$$

For Al-6wt.pct $\mathrm{Cu}$ alloy, $r=0.4, S_{\mathrm{s} 0}=2.46 \mu \mathrm{m}^{-1}$, and $K_{0}=23.5 \mu \mathrm{m}^{3} / \mathrm{s}$.

\section{B. Flow Effect on Fragmentation}

Melt convection has also been observed as a potent mechanism for the onset of fragmentation. ${ }^{[16]}$ In such cases, breakups occur owing to remelting of the roots of the secondary arms ${ }^{[1,17]}$ because of the flow-induced rise in temperature and/or solute enrichment.

Through X-ray synchrotron radiography, Mathiesen et al. ${ }^{[18]}$ provided clear evidence of a distinct fragmentation potential exhibited by solidification directions parallel and anti-parallel to gravity for Al-20 wt pet $\mathrm{Cu}$ and Al-30 wt pet $\mathrm{Cu}$ alloys. The arrangement in which solidification is parallel to gravity resulted in a lower 
fragmentation rate than the anti-parallel arrangement for both alloys. This was attributed to the stabilizing effect of the buoyancy force because for the alloys studied, the liquid phase was denser than the solid phase. These findings were later supported by Liotti et al. ${ }^{[19]}$ who studied the solidification of Al-15 wt pet $\mathrm{Cu}$ and $\mathrm{Al}-25$ wt pet $\mathrm{Cu}$ alloys in situ by synchrotron $\mathrm{X}$-ray radiography. In addition to the buoyancy force, the authors also investigated the effect of a pulsed electromagnetic field, which was associated with the intensification of the rate of fragmentation.

Nevertheless, the influence of the external field on fragmentation has been observed to be indirect. Several studies have found a delay between the beginning of forced flow (e.g., stirring) and the onset of crystal multiplication. ${ }^{[19,20]}$ This reinforces the concept that strengthened convection induces thermosolutal fluctuations that promote remelting, rather than mechanical fracture. Furthermore, the transport of solute-enriched melt toward the tip of high-order branches encourages growth by local undercooling and consequently local solute rejection. This leads to local solute enrichment at the root of the branches, which also promotes fragmentation by solute pileup. ${ }^{[18]}$ In this case, the dendritic network arrangement and direction relative to the flow have been shown to have a significant impact on fragmentation. ${ }^{[17]}$

Interdendritic flow is not only important for remelting but also as a dispersal mechanism for transporting fragments out of the mushy zone. Fragments that become sources of equiaxed grains must survive the potential melting conditions ahead of the columnar front. ${ }^{[1]}$ A stronger forced flow substantially increases the probability of survival of the fragments, ${ }^{[21]}$ which is a critical step for the occurrence of CET. ${ }^{[2]}$

According to Flemings' theory of local remelting, ${ }^{[23]}$ only the flow in the growth direction of the primary columnar dendrites promotes remelting of the dendrites. Based on this theory, Campanella et al. ${ }^{[24]}$ proposed a qualitative criterion for the onset of fragmentation. Fragmentation was considered if the component of the fluid flow velocity in the thermal gradient direction was larger than the speed of the isotherms, and the fragmentation location from the columnar primary dendrite tip was larger than 8 times the secondary dendrite arm spacing. In line with this flow-enhanced local remelting theory, Zheng et al. ${ }^{[25,26]}$ suggested a more practical solution to account for the fragmentation phenomenon in casting processes. A formulation was proposed to consider flow-enhanced remelting as the main source of fragmentation, and it was applied to a volume average model. However, this formulation failed to consider other contributing factors to the fragmentation mechanism, such as the curvature effect of the dendrites, latent heat-induced thermal fluctuation, and diffusion in the interdendritic melt. These factors were supposed to be integrated into a single coefficient that had to be determined experimentally through a parameter study.

\section{Fragmentation Frequency}

Several experiments have been conducted to count fragments for different alloys, e.g., with succinonitrile-acetone, ${ }^{[20]} \mathrm{NH}_{4} \mathrm{Cl}-\mathrm{H}_{2} \mathrm{O}$ solutions, ${ }^{[27]}$ and even with metal alloys. ${ }^{[18,19,28]}$ However, it is very difficult to establish a quantitative correlation between the fragmentation frequency and the experimentally controlled parameters, such as the cooling rate, forced flow rate, and initial alloy composition. More recently, Cool and Voorhees $^{[10]}$ performed isothermal coarsening experiments and discovered that the number of fragments from capillary-driven mechanisms was nearly invariant when scaled by the cube of the specific surface area of the dendrites $\left(S_{\mathrm{s}}\right)$.

Alternatively, an indirect method using "fitting" parameters to match the experimental results was suggested by Lesoult ${ }^{[29]}$. It was assumed that stirring molten steel ahead of the solidification front would result in a seeding liquid with dendritic fragments. Presumably, those fragments eroded from the columnar front with a fragment flux of $8 \mathrm{~cm}^{-2} \mathrm{~s}^{-1}$, as determined from metallographic observations of slab sections. This idea was later implemented into a volume average solidification model to consider fragmentation during mixed columnar-equiaxed solidification. ${ }^{[30]}$ A shortcoming of this method is that the experimentally determined relationship of the fragment flux from the columnar tip front is not directly related to any physics-based mechanism of fragmentation.

In this study, both capillary-driven and flow-enhanced fragmentation mechanisms are combined in a comprehensive three-phase volume average solidification model. The implementation of the interfacial area density was validated against the phase-field simulations of Neumann-Heyme et al. ${ }^{[15]}$ The fragmentation formulation was extended to non-isothermal conditions by modifying the original equation for the number of fragments proposed by Cool and Voorhees ${ }^{[10]}$. The simulation results were analyzed in terms of the effects of melt convection and crystal sedimentation on the fragmentation output and CET dynamics.

\section{MODEL DESCRIPTION}

\section{A. Mixed Columnar-Equiaxed Solidification}

The three-phase model for mixed columnar-equiaxed solidification used in this study has been described in detail elsewhere ${ }^{[31,32]}$ so only a summary is given below.

The three phases (liquid, solid columnar, and solid equiaxed) are treated explicitly, and their volume fractions $\left(f_{\ell}, f_{\mathrm{c}}, f_{e}\right)$ add up to one. The columnar phase is always rigid and stationary. The other two phases can move, and the corresponding momentum conservation equations are solved. Species and enthalpy conservation equations are calculated for all three phases, and an additional transport equation for the equiaxed phase is solved to account for the evolution of the number of grains created by fragmentation. 
Heterogeneous nucleation is neglected, which assumes that the equiaxed crystals can only originate from fragmentation. The net mass transfer rate from liquid to solid is calculated according to the growth velocity of the solid phase. It is governed by solute diffusion in the interdendritic melt and the concentration difference $\left(c_{\ell}{ }^{*}\right.$ $-c_{\ell}$ ) acts as the driving force for solidification. Thermodynamic equilibrium is assumed at the solid-liquid interface, which determines the species concentration at the interface $c_{\ell}{ }^{*}$. Back diffusion in the solid $\left(D_{\mathrm{c}}\right.$, $\left.D_{\mathrm{e}}=0\right)$, as well as solidification shrinkage, is neglected. The dendrite tip growth kinetics are calculated according to Lipton-Glicksman-Kurz (LGK) model. ${ }^{[33]}$ The thermosolutal convection of the melt and crystal sedimentation are modeled using the Boussinesq approximation. A linearized $\mathrm{Al}-\mathrm{Cu}$ binary phase diagram is used, with constant solute redistribution coefficient $k$ and liquidus slope $m$. Simple crystal morphologies are assumed for the diffusion-governed solidification kinetics: spheres for equiaxed grains and stepwise cylinders for columnar tree trunks. Re-melting of fragments was not considered in this work.

\section{B. Fragmentation Model}

A schematic of the fragmentation process is illustrated in Figure 2. The exchange of mass between columnar and equiaxed dendrites due to fragmentation can be accounted for via a mass transfer term between the two solid phases. In the present study, this parameter follows the concept proposed by Zheng et al., ${ }^{[25]}$ where the mass transfer between columnar and equiaxed phases $M_{\mathrm{ce}}$ is determined by multiplying the fragmentation rate $\dot{N}_{\mathrm{V}}$ by the volume of the detached fragment:

$$
M_{\mathrm{ce}}=\dot{N}_{\mathrm{V}}\left(\rho_{\mathrm{e}} \frac{\pi}{6}\left(d_{\mathrm{frag}}^{0}\right)^{3}\right) .
$$

The fragmentation rate $\dot{N}_{\mathrm{V}}$ has been introduced in Eq. [1]. However, two important changes have been made to this equation, which are described in the following.

Cool and Voorhees ${ }^{[10]}$ reported that the number of fragments was nearly invariant when scaled by the cube of $S_{\mathrm{s}}$. Because of the isothermal nature of the experiments, the characteristic length scale assumed by the authors only considered the coarsening stage (i.e., the one given by Eq. [2]). In the present study, to also capture the morphological evolution of the dendritic structure during the solidification-dominant stage, the more comprehensive $S_{\mathrm{S}}$ presented in Eq. [3] is used instead of Eq. [2].

Since $S_{\mathrm{S}}$ is known to decrease with time in both isothermal and non-isothermal (cooling) conditions, $N_{\mathrm{V}}$ will also continuously decrease with time. This is inconsistent with the experimental evidence that shows a net positive fragmentation rate at the beginning of the solidification-dominant stage ${ }^{[19]}$. Here, we propose replacing $S_{\mathrm{S}}$ in Eq. [1] with $S_{\mathrm{V}}$, which yields

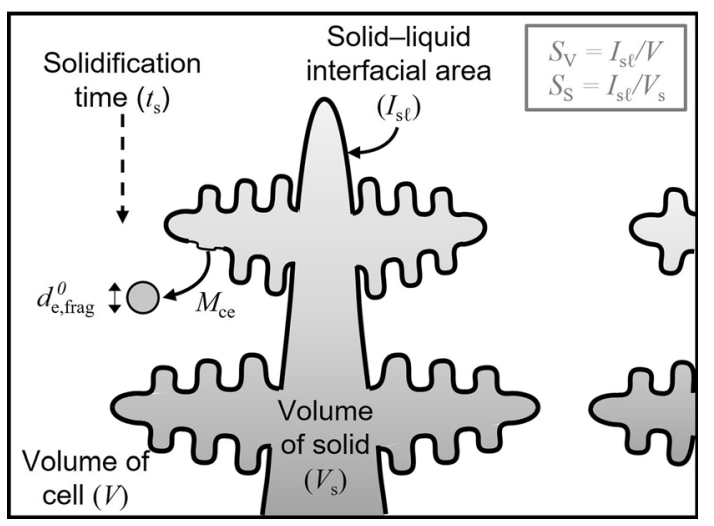

Fig. 2-Schematic of the fragmentation process and parameters of interest.

$$
\dot{N}_{\mathrm{V}}=\frac{\mathrm{d}\left(a \cdot S_{\mathrm{V}}^{3}\right)}{\mathrm{d} t}
$$

These two changes will provide a more realistic model of the fragmentation behavior during the growth of the dendritic structure without affecting the agreement with the measurement data of Cool and Voorhees ${ }^{[10]}$. This will be discussed in detail later. Note that the constant $a$ in Eq. [5] was set as $0.5 \times 10^{-4}$ for the Pb-Sn samples. ${ }^{[10]}$ To the best of our knowledge, no information is available for other alloys, such as Al-Cu. Therefore, the current value of $a$ is also used here.

The initial size of the fragments needs to be estimated as well. Normally, the fragments have different shapes when they detach from the columnar structure. However, due to the lack of accurate description of each individual shape, the initial fragment is assumed to be globular. Its diameter is taken as the product of the time-dependent secondary dendrite arm spacing $\left(\lambda_{2}\right)$ and the volume fraction of the columnar phase $\left(f_{\mathrm{s}}\right)^{[25]}$ : $d_{\text {frag }}^{0}=\lambda_{2} f_{s}$. Li and Beckermann ${ }^{[34]}$ observed in their experimental studies with pure succinonitrile dendrites that $S_{\mathrm{V}}$ can be related to $\lambda_{2}$ by $S_{\mathrm{V}}=1.6 / \lambda_{2}$, which leads to the following relation for the initial size of the fragments:

$$
d_{\text {frag }}^{0}=f_{s} \frac{1.6}{S_{\mathrm{V}}}
$$

Although this relationship is valid only for conditions where dendritic growth is the dominant mechanism, it will be used here across the entire solidification spectrum to relate fragment size directly to $S_{\mathrm{V}}$. The interfacial area density for the entire spectrum is calculated as follows:

$$
S_{\mathrm{V}}=f_{s}\left(1-f_{s}\right)^{\mathrm{r}}\left(S_{\mathrm{s} 0}^{-3}+K_{0} t_{\mathrm{s}}\right)^{-1 / 3}
$$

It is worth highlighting that the local solidification time $\left(t_{\mathrm{s}}\right)$ of a computational cell starts once the 
columnar tip reaches the cell. Fragmentation occurs only when a certain amount of columnar phase develops locally. Owing to the lack of experimental data, a value of 0.1 was taken for the minimal volume fraction of the columnar phase $\left(f_{\mathrm{c} \text { onset }}^{\mathrm{rag}}\right)$ for the onset of fragmentation. From parameter studies, it was found that this choice does not significantly affect the results as long as the value corresponds to relatively small solid fractions. This is because if a small $f_{\mathrm{c}, \text { onset }}^{\text {rrag }}$ is considered, corresponding to a dendritic structure with a small number of side branches, $N_{\mathrm{V}}$ will be minor owing to the small $f_{\mathrm{s}}$ and $S_{\mathrm{V}}$. This number of fragments will become negligible when $S_{\mathrm{V}}$ increases and a much greater number of

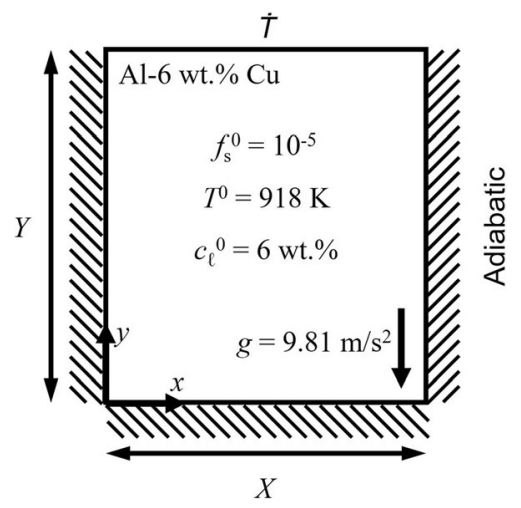

Fig. 3 - Geometry and boundary conditions of Setups 1 and 2. fragments are produced (as $N_{\mathrm{V}} \propto S_{\mathrm{V}}{ }^{3}$ ). However, $f_{\mathrm{c}, \text { onset }}^{\text {frag }}$ should not be excessively small because it might lead to fragmentation in an underdeveloped columnar structure.

In summary, once fragmentation occurs locally (i.e., positive $\dot{N}_{\mathrm{V}}$ ), mass is transferred directly from the columnar to the equiaxed phase (via $M_{\mathrm{ce}}$ ), and the solid fraction of both phases is updated (i.e., the solid fraction of the columnar phase decreases, whereas the equiaxed solid fraction increases). After that, fragmentation can still occur in the same columnar structure if the local columnar solid fraction is above $f_{\mathrm{c} \text {,onset }}^{\mathrm{frag}}$. The presence of fragments within the columnar structure does not affect the potential for fragmentation nor changes the "onset of fragmentation" limit. Multiplication of fragments ${ }^{[2]}$ (i.e., further fragmentation of created fragments) is not considered.

\section{Test Case Configuration}

Two sets of simulations were performed, namely Setup 1 and Setup 2. Their geometries and corresponding boundary and initial conditions are shown in Figure 3. The material properties and other process conditions are listed in Table I. The two-dimensional computational domains are meshed using 3000 cells.

In Setup 1, the flow and crystal sedimentation are not considered. The purpose of this case is to verify the implementation of the fragmentation model. The

Table I. Material Properties and Other Process Parameters Used in the Simulations

\begin{tabular}{|c|c|c|c|c|}
\hline \multirow[b]{2}{*}{ Nominal Composition } & \multirow{2}{*}{$\frac{\text { Symbol }}{c_{0}}$} & \multicolumn{2}{|c|}{ Al-6 Weight Percent $\mathrm{Cu}$} & \multirow{2}{*}{$\frac{\text { Unit }}{\text { Wt pct }}$} \\
\hline & & 6.0 & & \\
\hline Liquidus Temperature & $T_{\text {liq }}$ & 917.5 & & $\mathrm{~K}$ \\
\hline Melting Point of Solvent at $c_{0}=0$ & $T_{\mathrm{f}}$ & 933.15 & & K \\
\hline Eutectic Composition & $c_{\text {eut }}$ & 32.6 & & wt pet \\
\hline Eutectic Temperature & $T_{\text {eut }}$ & 821.4 & & $\mathrm{~K}$ \\
\hline Liquidus Slope & $m$ & -3.440 & & $\mathrm{~K}$ \\
\hline Eq. Partition Coefficient & $k$ & 0.14 & & - \\
\hline Packing Limit & $f_{\mathrm{e}}^{\mathrm{c}}$ & 0.19 & & - \\
\hline Reference Density & $\rho_{\text {ref }}$ & 2606.0 & & $\mathrm{Kg} \mathrm{m}^{-3}$ \\
\hline Specific Heat of Liquid & $c_{\mathrm{p}}^{\ell}$ & 1179.0 & & $\mathrm{~J} \mathrm{~kg}^{-1} \mathrm{~K}^{-1}$ \\
\hline Specific Heat of Solid & $c_{\mathrm{p}} \mathrm{p}_{\mathrm{s}}$ & 766.0 & & $\mathrm{~J} \mathrm{~kg}^{-1} \mathrm{~K}^{-1}$ \\
\hline Thermal Conductivity of Liquid & $k_{\ell}$ & $7700.0($ setup 1$)$ & 77.0 (setup 2) & $\mathrm{W} \mathrm{m} \mathrm{m}^{-1} \mathrm{~K}^{-1}$ \\
\hline Thermal Conductivity of Solid & $k_{\mathrm{s}}$ & $15300.0(\operatorname{setup} 1)$ & $153.0(\operatorname{setup} 2)$ & $\mathrm{W} \mathrm{m^{-1 }} \mathrm{K}^{-1}$ \\
\hline Latent Heat & $\dot{L}$ & $3.97 \times 10^{5}$ & & $\mathrm{~J} \mathrm{~kg}^{-1}$ \\
\hline Viscosity of Liquid & $\mu_{\ell}$ & 0.0012 & & $\mathrm{~kg} \mathrm{~m}^{-1} \mathrm{~s}^{-1}$ \\
\hline Liquid Thermal Expansion Coefficient & $\beta_{\mathrm{T}}$ & $0.0($ setup 1$)$ & $10^{-4}(\operatorname{setup} 2)$ & $\mathrm{K}^{-1}$ \\
\hline Liquid Solutal Expansion Coefficient & $\beta_{\mathrm{C}}$ & $0.0($ setup 1$)$ & $-0.92($ setup 2$)$ & wt. $\%{ }^{-1}$ \\
\hline Primary Dendritic Arm Spacing & $\lambda_{1}$ & $1.4 \times 10^{-4}($ setup 1$)$ & $4.0 \times 10^{-4}($ setup 2$)$ & $\mathrm{m}$ \\
\hline Diffusion Coefficient in Liquid & $D_{\ell}$ & $3.0 \times 10^{-9}$ & & $\mathrm{~m}^{2} \mathrm{~s}^{-1}$ \\
\hline Diffusion Coefficient in Solid & $D_{\mathrm{s}}$ & $3.0 \times 10^{-13}$ & & $\mathrm{~m}^{2} \mathrm{~s}^{-1}$ \\
\hline Initial Temperature & $T_{0}$ & 918 & & $\mathrm{~K}$ \\
\hline Heat Transfer Coefficient & $h$ & 0.0 & & $\mathrm{~W} \mathrm{~m}^{-2} \mathrm{~K}^{-1}$ \\
\hline Solid-Liquid Density Difference & $\Delta \rho$ & $0.0($ setup 1$)$ & 137.0 (setup 2) & $\mathrm{kg} \mathrm{m}^{-3}$ \\
\hline Gibbs-Thomson Coefficient & $\vec{\Gamma}$ & $2.4 \times 10^{-7}$ & & $\mathrm{~m} \mathrm{~K}$ \\
\hline Cooling Rate & $\dagger$ & $6.0($ setup 1$)$ & 0.12 (setup 2) & $\mathrm{K} \mathrm{s}^{-1}$ \\
\hline Domain Height & $Y$ & $0.035($ setup 1$)$ & 0.14 (setup 2) & $\mathrm{m}$ \\
\hline Domain Width & $X$ & $0.014($ setup 1$)$ & $0.14($ setup 2) & $\mathrm{m}$ \\
\hline
\end{tabular}


modeling results are compared with those of the NEB model ${ }^{[15]}$ and an analytical solution. Neumann-Heyme et $a .^{[15]}$ employed a phase-field model to replicate the directional solidification of a dilute binary alloy (Al-6 wt pct $\mathrm{Cu}$ ) in a very small calculation domain with a very high cooling rate $(6 \mathrm{~K} / \mathrm{s})$. In the present volume average solidification model, a larger calculation domain is considered such that each computational cell is much larger than the primary dendritic arm spacing. Moreover, the heat conductivity of the alloy is artificially multiplied by 100 to obtain a homogeneous temperature across the domain (similar to that in the phase-field simulations). For the analytical solution, the Scheil equation is used to calculate the solid fraction curve $\left(f_{\mathrm{s}}-T\right)$, and the interfacial area density $\left(S_{\mathrm{V}}\right)$ is calculated from Eq. [7].

The conditions employed in Setup 2 are more consistent with the casting applications found in industrial processes. The cooling rate is smaller, and thermosolutal convection and crystal sedimentation are included. The flow boundary conditions are no slip for both the liquid and solid phases. $\lambda_{1}$ has been adjusted to agree with the experimental evidence found in the literature for the cooling conditions used in this setup. ${ }^{[35-37]}$ Note that the initial temperature of the melt inside the domain is set to $918 \mathrm{~K}$ (only $0.5 \mathrm{~K}$ above $T_{\text {liq }}$ ) to avoid re-melting of the fragments.

\section{SIMULATION RESULTS}

\section{A. Setup 1}

The simulated $f_{\mathrm{s}}-t_{\mathrm{s}}$ curve was compared with those from the phase-field simulation of the NEB model and the Scheil equation, as displayed in Figure 4(a). The results were saved $10 \mathrm{~s}$ after the start of the simulation and were taken along a vertical line located at mid width and spanning the entire domain longitudinally. The curves from both simulations are plotted against the local solidification time $\left(t_{\mathrm{s}}\right)$, whereas the classical Scheil equation assumes that solidification starts immediately from the liquidus temperature. Although the curves are plotted as functions of different definitions of time, the origin of the $x$-axis has been set to match the onset of solidification in all cases. The $f_{\mathrm{s}}-T$ curves are also shown in the inset of Figure 4(a) and demonstrates that solidification in both simulations start at a larger undercooling than the classical Scheil equation. This can justify the discrepancy between the simulations and Scheil equation shown in Figure 4(a). Nevertheless, the agreement between the two simulations is good considering the extreme cooling rate $(6 \mathrm{~K} / \mathrm{s})$ of this setup and the difference in the geometric dimensions.

In Figure $4(\mathrm{~b})$, the $S_{\mathrm{V}}-t_{\mathrm{s}}$ curve obtained with the present model is compared with the curves from the phase-field simulation of the NEB model and the Scheil equation. Again, a good agreement is observed between the simulation results.

The computations for the simulation results of the present model illustrated in Figure 4 took about $12 \mathrm{~h}$ using 1 CPU. In comparison, the computations of NEB were carried out on a high-performance computing

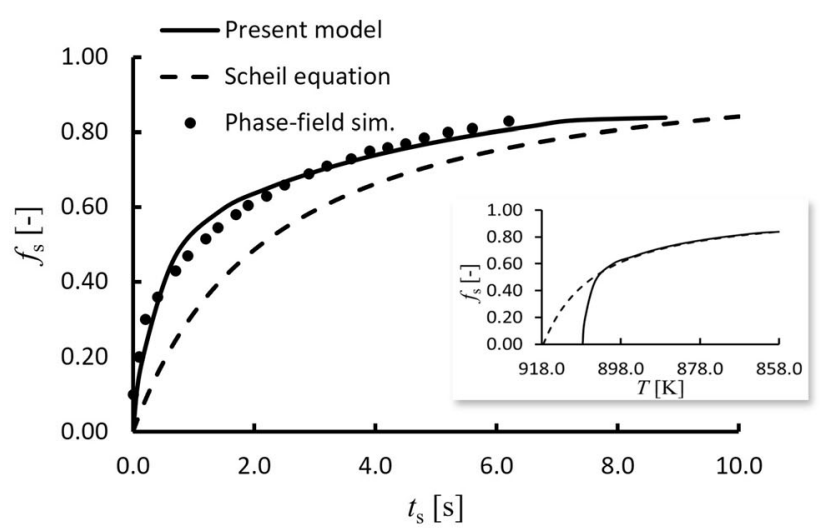

(a)

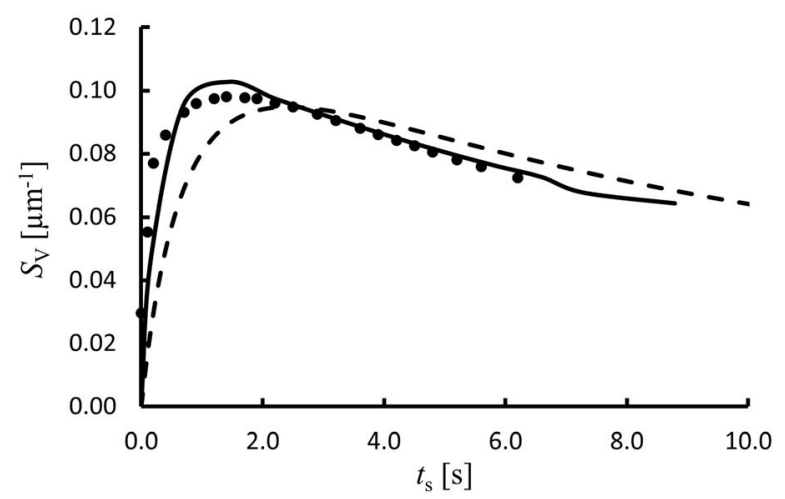

(b)

Fig. 4-Modeling results for Setup 1 of $(a) f_{s}$ and (b) $S_{\mathrm{V}}$ as functions of $t_{\mathrm{s}}$. The solid black line corresponds to the results of the present volume average model along the longitudinal line, the dashed black line is the Scheil equation obtained by assuming a $6 \mathrm{~K} / \mathrm{s}$ cooling rate and starting from the liquidus temperature, and the black dots are the results of the phase-field simulation performed using the NEB model. The inset in (a) represents the solid fraction evolution as a function of temperature for the present model and the Scheil equation.

(HPC) cluster using 512 CPUs and their base case simulation took them about one week of time.

As discussed in the previous section, to extend the range of applicability of $\dot{N}_{\mathrm{V}}$ to the non-isothermal (solidification dominant) stage, the original equation proposed by Cool and Voorhees ${ }^{[10]}$ presented in Eq. [1] has been modified to Eq. [5]. The corresponding fragmentation rate $\left(\dot{N}_{\mathrm{V}}\right)$ and number of fragments $\left(N_{\mathrm{V}}\right)$ are shown in Figure 5(a).

Considering that the solidification-dominant stage is characterized by substantial dendritic growth and sidebranch formation, $S_{\mathrm{V}}$ increases steeply during the first 2 $\mathrm{s}$, which in turn leads to an increase in $N_{\mathrm{V}}$, as exhibited in Figure 5(a). After reaching the maximum value, the total $N_{\mathrm{V}}$ decreases gradually owing to the significant progression of the coarsening effect on the dendritic morphology. This change in the characteristics of the process is captured by the positive-to-negative shift of the $\dot{N}_{\mathrm{V}}-t_{\mathrm{S}}$ curve (right axis).

A comparison between the newly proposed equation for $N_{\mathrm{V}}$ and the original version derived from Eq. [1] is presented in Figure 5(b). The black circles and black 


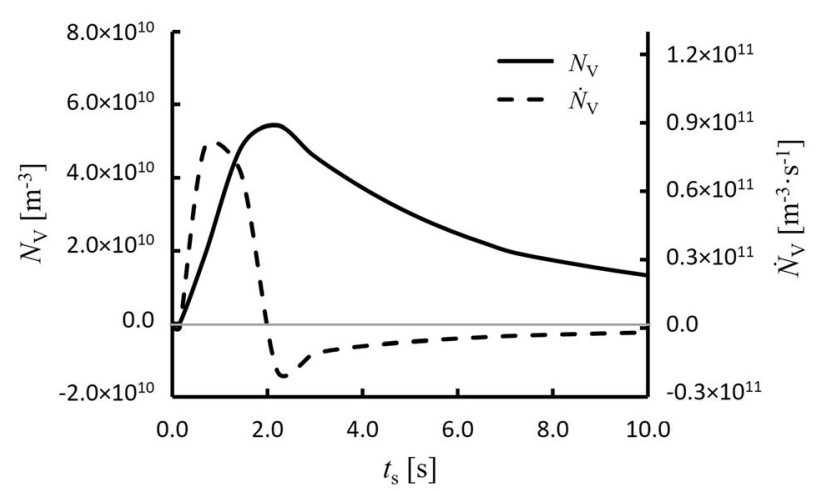

(a)

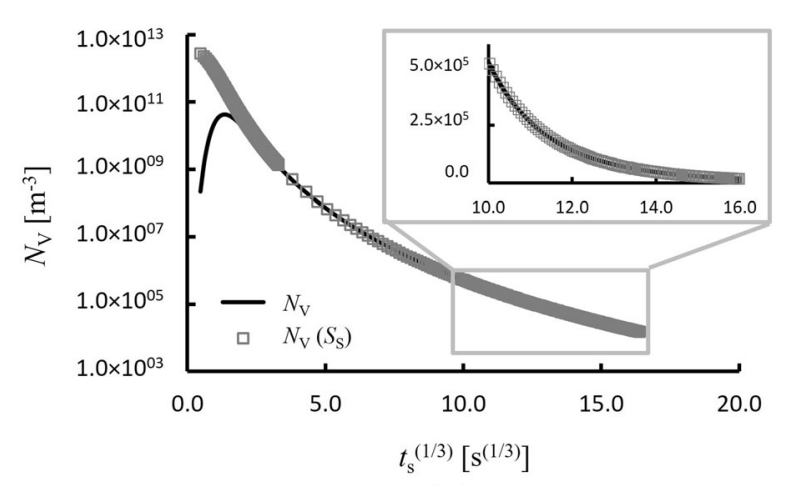

(b)

Fig. 5-Modeling results for Setup 1 of (a) $N_{\mathrm{V}}$ (left axis) and $\dot{N}_{\mathrm{V}}$ (right axis) as functions of $t_{\mathrm{s}}$ and $(b)$ comparison between $N_{\mathrm{V}}$ calculated using Eq. [1] $\left(N_{\mathrm{V}}\left(S_{\mathrm{S}}\right)\right)$ and using Eq. [5] $\left(N_{\mathrm{V}}\right)$. The $y$-axis in (b) has a logarithmic scale and the inset highlights the agreement between both curves in the late coarsening stage.

lines indicate the values of $N_{\mathrm{V}}$ derived from Eq. [1] and Eq. [5], respectively, which are labeled as " $N_{\mathrm{V}}\left(S_{\mathrm{S}}\right)$ " and " $N_{\mathrm{V}}$." The $y$-axis is set with a logarithmic scale, whereas in the $x$-axis, the local solidification time $\left(t_{\mathrm{s}}\right)$ is raised to a power of $1 / 3$.

$N_{\mathrm{V}}\left(S_{\mathrm{S}}\right)$ decreases consistently with $t_{\mathrm{s}}$. On the other hand, by employing $S_{\mathrm{V}}$ instead of $S_{\mathrm{S}}, N_{\mathrm{V}}$ increases rapidly during the solidification-dominant stage and then decreases in the coarsening-dominant stage. This behavior has been observed in Figure 5(a) and seems to be more consistent with the physics underlying fragmentation during solidification. Nevertheless, despite the critical difference in the solidification-dominant stage, in the coarsening-dominant stage, the two curves match each other perfectly, as depicted by the inset in Figure 5(b). Therefore, beyond extending the range of applicability of the model to the solidification-dominant stage, Eq. [5] is still valid for the work by Cool and Voorhees $^{[10]}$ during the coarsening-dominant stage.

\section{B. Setup 2 Without Solid Motion}

To facilitate the analysis of the results, the first simulation for Setup 2 was made by "fixing" the equiaxed crystals. The thermosolutal convection of the melt was calculated, but the newly created crystal fragments and subsequently developed equiaxed crystals were assumed to be stationary. For numerical reasons, the simulation must be initialized with a small number density of equiaxed crystals $\left(10^{6} 1 / \mathrm{m}^{3}\right)$ in the entire calculation domain. This should be considered in the analysis of the subsequent simulation results.

Columnar structures develop from the top surface where cooling starts. The evolutions of $f_{\mathrm{c}}$ and $S_{\mathrm{V}}$ along the vertical axis at three different moments are depicted in Figures 6(a) and (b). At $t=100 \mathrm{~s}, f_{\mathrm{c}}$ reaches approximately 0.40 , and the corresponding microstructure has a maximum $S_{\mathrm{V}}$ of $2.8 \times 10^{4} \mathrm{~m}^{-1}$. At $t=400 \mathrm{~s}$, the columnar structure reaches almost half of the entire domain, and $f_{\mathrm{c}}$ extends up to almost 0.8 . $S_{\mathrm{V}}$ increases rapidly from the columnar tip, reaches a maximum value, and then decreases deep into the mushy zone where the coarsening-dominant stage exists. At $t=800$ s, similar patterns can be observed.

Snapshots representing the distribution of the number density of equiaxed crystals (fragments) $n_{\mathrm{eq}}$ at $t=100$, 400 , and $800 \mathrm{~s}$ are shown in Figures 6(c) through (e). $n_{\mathrm{eq}}$ reaches its maximum value rapidly near the columnar primary dendrite tip and then declines because of coarsening. Furthermore, the absolute maximal value of $n_{\mathrm{eq}}$ observed at $t=100 \mathrm{~s}$ decreases during the solidification sequence. For instance, at $t=100 \mathrm{~s}$ in the top region, $n_{\text {eq }}$ is approximately $1.0 \times 10^{9}$. However, in the following snapshots, because of the continuous increase in $t_{\mathrm{s}}$ combined with the reduction in the dendritic growth magnitude, $n_{\mathrm{eq}}$ reduces to approximately $4.0 \times 10^{8}$ at $t=400 \mathrm{~s}$ and then to less than $2.0 \times$ $10^{8}$ at $t=800 \mathrm{~s}$.

The results of $f_{\mathrm{c}}, S_{\mathrm{V}}$ and $N_{\mathrm{V}}$ as functions of $t_{\mathrm{s}}$ at $t=$ $800 \mathrm{~s}$ for Setup 2 are plotted in Figure 7. Compared to the results for Setup 1, $f_{\mathrm{c}}$ in Setup 2 increases at a much slower pace owing to the more modest cooling rate. Instead of the $10 \mathrm{~s}$ time frame presented in Figures 4 and 5 for Setup 1, the simulation takes approximately $800 \mathrm{~s}$ to reach the same $f_{\mathrm{c}}$. Consequently, $S_{\mathrm{V}}$ in Setup 2 has a much smaller maximum value (Figure $7(\mathrm{~b})$ ) than in Setup 1, which leads to a significant reduction in the maximum number of fragments (Figure 7(c)). The insets in Figures 7(a) through (c) represent the same quantities $\left(f_{\mathrm{c}}, S_{\mathrm{V}}\right.$, and $\left.N_{\mathrm{V}}\right)$ as functions of the temperature for Setups 1 and 2. The general trends of the two setups are preserved for all quantities.

From the constant $\lambda_{1}$ assumed in this study and the average $\lambda_{2}$ calculated at the end of the coarsening stage (i.e., $5 \times 10^{-5} \mathrm{~m}$ ), one can evaluate the total number of secondary arms that can potentially lead to fragmentation. We estimated an average of $5 \times 10^{11}$ secondary $\mathrm{arms} / \mathrm{m}^{3}$ in Setup 2. This means that the maximum number of fragments predicted in Figure 7(c) corresponds to a very small fraction (approximately $0.15 \mathrm{pct}$ ) of the total number of arms per unit of volume inside the domain, which seems a reasonable estimate considering that fragmentation only occurs over a limited range of conditions. ${ }^{[7]}$

Interestingly, an irregular solidification front at the columnar primary dendrite tip can be observed in Figure 8 (a) at $t=500 \mathrm{~s}$. This mushy zone instability is due to the liquid flow, as illustrated by the liquid velocity vectors. If thermosolutal convection was 


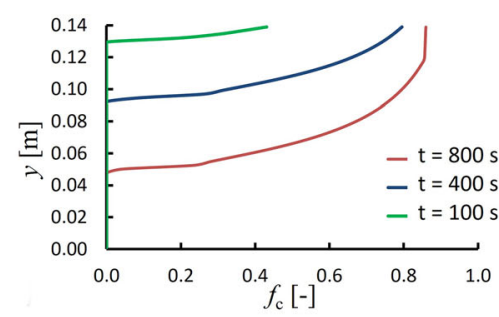

(a)

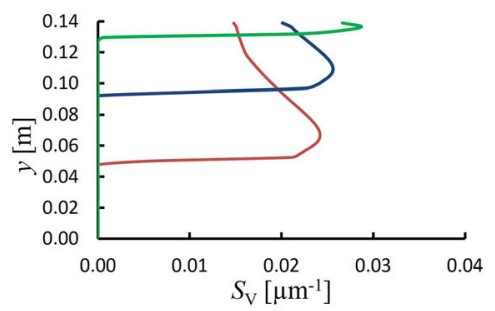

(b)

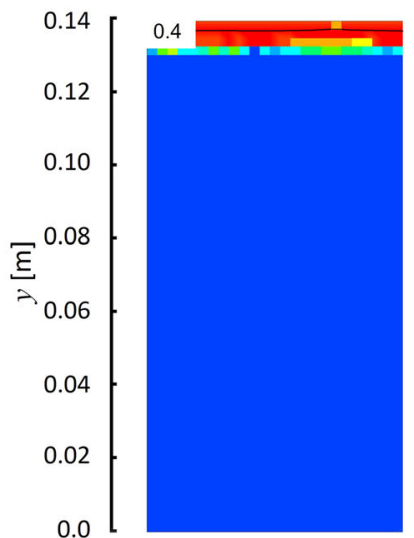

(c)

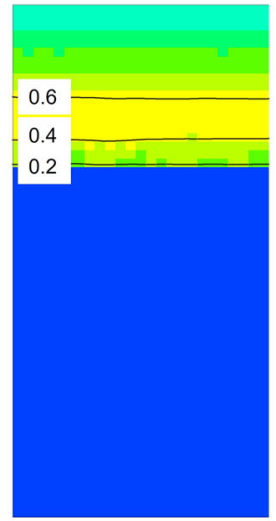

(d)

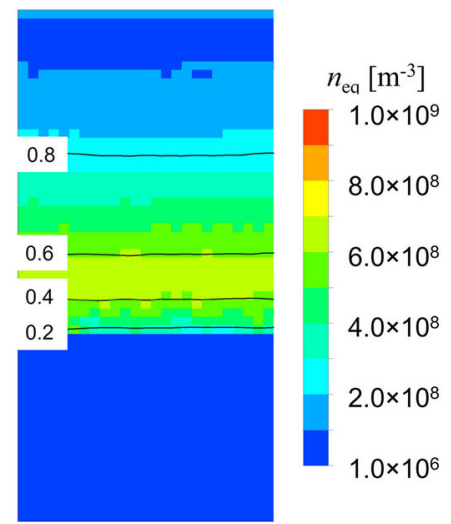

(e)

Fig. 6-Modeling results for Setup 2 (without solid motion) of $(a) f_{\mathrm{c}}$ and $(b) S_{\mathrm{V}}$ along the longitudinal axis at $t=100$, 400, and $800 \mathrm{~s}$. Distribution of $n_{\mathrm{eq}}$ overlaid with isolines of $f_{\mathrm{c}}$ at $(c) t=100 \mathrm{~s},(d) t=400 \mathrm{~s}$, and $(e) t=800 \mathrm{~s}$. As solidification is unidirectional, only a part of the domain is shown for (c) through (e).

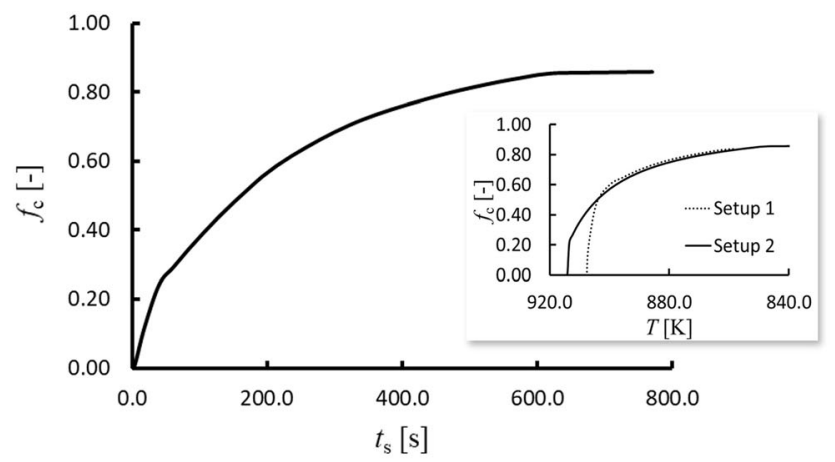

(a)

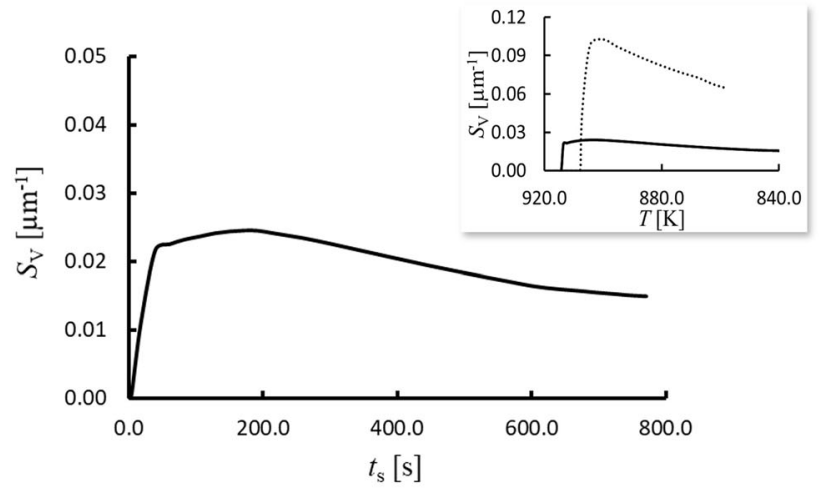

(b)

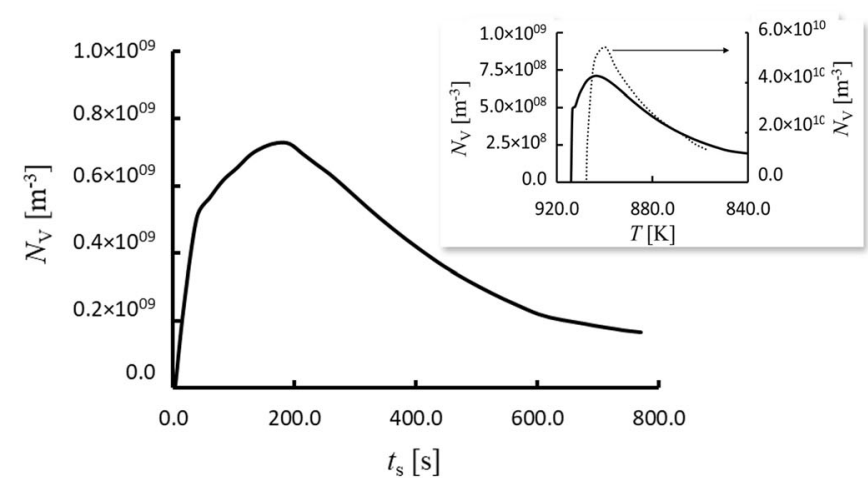

(c)

Fig. 7-Modeling results for Setup 2 (without solid motion) of $(a) f_{\mathrm{c}},(b) S_{\mathrm{V}}$, and $(c) N_{\mathrm{V}}$ as functions of $t_{\mathrm{s}}$ at $t=800 \mathrm{~s}$. The insets depict the same quantities as functions of $T$ and include the simulation results obtained in Setup 1 for reference.

neglected (as in Setup 1), the solidification front would be perfectly flat. To analyze the effect of flow on the fragmentation mechanism, Figure $8(\mathrm{~b})$ presents the variation of $N_{\mathrm{V}}$ as a function of $t_{\mathrm{s}}$ along two vertical lines located at positions where the melt is moving in opposite directions (labeled "w/ flow (up)" and "w/ flow (down)"). For comparison, an additional $N_{\mathrm{V}}-t_{\mathrm{s}}$ curve is included, which shows the simulation results for Setup 2, neglecting both thermosolutal convection and solid motion ("no flow"). 


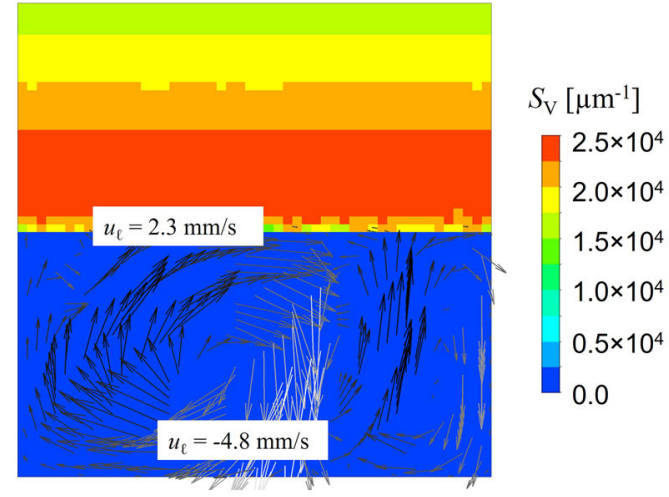

(a)

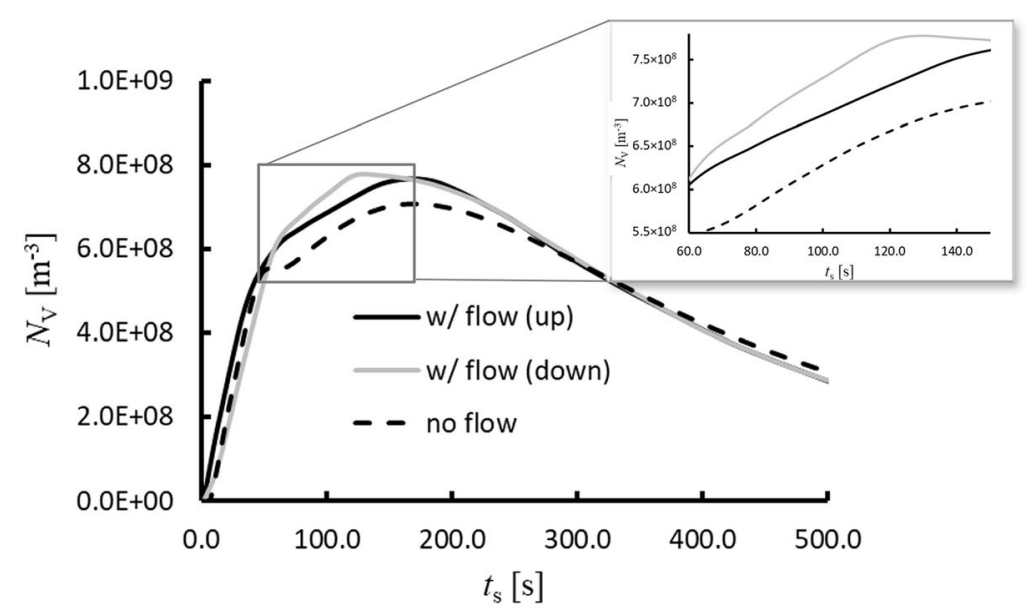

(b)

Fig. 8- (a) Flow-induced instability of the solidification front in Setup 2. The distribution of $S_{\mathrm{V}}$ is overlaid with the liquid velocity vectors $u_{\ell}$ at $t=500 \mathrm{~s}$. The largest positive (black arrows) and negative (white arrows) values from the liquid velocity range are shown in the snapshot. (b) $N_{\mathrm{V}}-t_{\mathrm{s}}$ curve along the vertical line spanning the entire domain for cases with and without the effect of melt convection in Setup 2 . With melt convection, two $N_{\mathrm{V}}-t_{\mathrm{s}}$ curves are plotted corresponding to vertical lines where the flow is moving in opposite directions in the bulk melt at $t=$ $500 \mathrm{~s}$.

Although the flow direction is dynamic during the course of solidification, the inset in Figure 8(b) indicates that during the solidification-dominant stage, $N_{\mathrm{V}}$ differs locally depending on the direction of the flow. This difference increases as the magnitude of the flow velocity increases. Furthermore, these simulation results are consistent at different moments within the coarsening-dominant stage and at distinct locations inside the domain. As the maximum $N_{\mathrm{V}}$ is reached and the coarsening-dominant stage approaches, the three curves gradually converge toward the same result.

\section{Setup 2 with Both Crystal Sedimentation and Melt Convection}

Setup 2 was made three dimensional (3D) by adding a depth of $28 \mathrm{~mm}$ to the domain. The front and back surfaces were considered as no-slip walls. The new computational domain was meshed with $3 \times 10^{4}$ cells. The solidification sequence is shown in Figure 9 for (from top to bottom) $f_{\mathrm{e}}, M_{\ell \mathrm{e}}$ (i.e., mass transfer between the liquid and equiaxed solid), $\dot{N}_{\mathrm{V}}, T$ (temperature), and $c_{\ell}$ (melt concentration). For easier visualization of the internal dynamics at different positions, different sections of the full domain are illustrated. On the right side, the contour plane is set midway between the front and back walls, whereas on the left side, the contour plane is set $5 \mathrm{~mm}$ away from the front wall. Equiaxed velocity vectors are exhibited on the right plane, and the columnar tip front is identified with a black line on the left plane.

At $t=80 \mathrm{~s}$, as the columnar structure develops from the upper surface, fragments are created as the source of equiaxed crystals (Figure 9(a)-(1) through (c)-(1)). With time, the fragments, which are heavier than the liquid, fall into the bulk melt and pile up at the bottom (Figure 9(a-2) and 9(a-3)). The corresponding grain growth during this sequence can be observed in
Figure 9(b-1) through 9(b-3). Figure 9(c-1) through 9(c-3) show that the fragmentation rate is larger near the columnar primary dendrite tip, and then decreases toward the root of the columnar network. The negative values indicate a decline in the number of fragments during dendrite coarsening. To provide more information on the grain development, the thermal and solutal evolutions are presented in Figure 9(d-1) through (d-3) and Figure 9(e-1) through (e-3), respectively.

A structural transition from columnar to equiaxed, i.e., CET, occurs when the equiaxed crystal packing bed blocks the growth of the columnar front. Although the crystal fragments formed near the columnar dendrite front fall into the bulk melt, many fragments that are stuck in the dendritic network still exist. As displayed in Figure 10, a significant number of fragments can be detected in the upper region of the mushy zone because the newly created fragments in the later stage of dendrite coarsening cannot be transported out of it, owing to the higher volume fraction of columnar dendrites. In this model, a large drag force coefficient between the solid phases is assumed when the local volume fraction of the columnar phase is above an arbitrary value of $0.2 .^{[32]}$ This assumption ensures that the equiaxed grains are captured by the mushy zone when the columnar solid fraction increases and the interdendritic space decreases.

To analyze the CET event, the evolutions of the columnar dendrite tip front and that of the packed equiaxed bed are plotted in Figure 11(a). The coordinate $(y)$ is taken along a centered vertical line and is normalized with the height of the calculation domain $(Y)$. The results suggest that both front positions develop in an approximately linear manner. The pileup of the packed equiaxed bed is much slower than that of the columnar tip front. At $t=1100 \mathrm{~s}$, the two dendritic regions meet in the lower part of the domain and block each other. This is illustrated in Figure 11(b), which shows an inverse gray-scale color map of the solid 


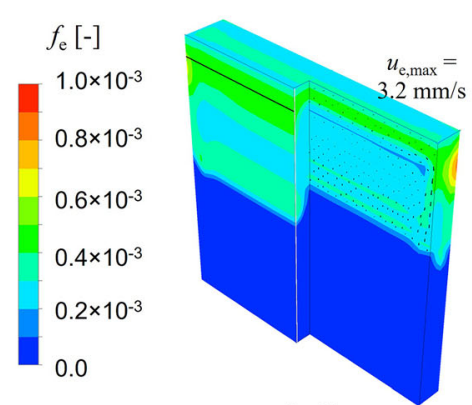

(a1)

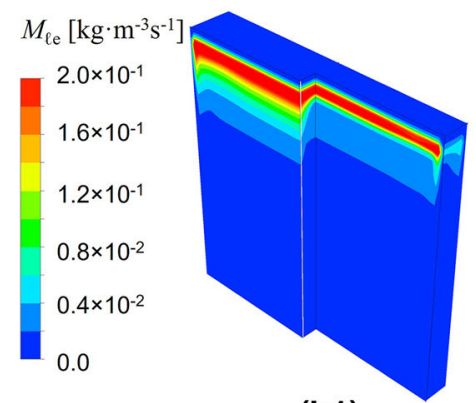

(b1)
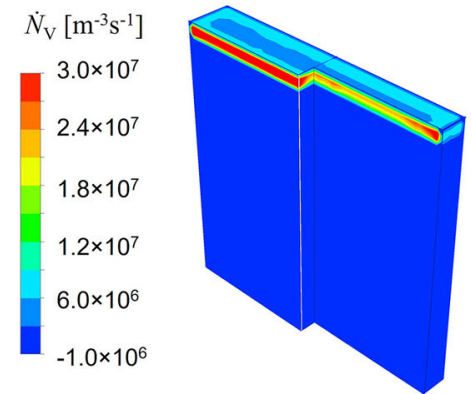

(c1)
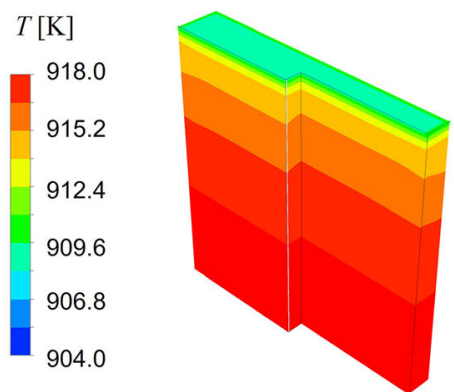

(d1)

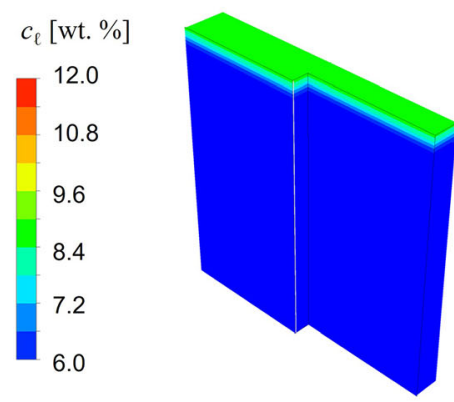

(e1)

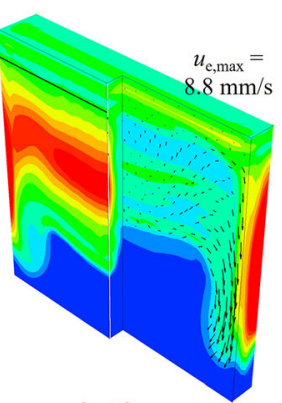

(a2)

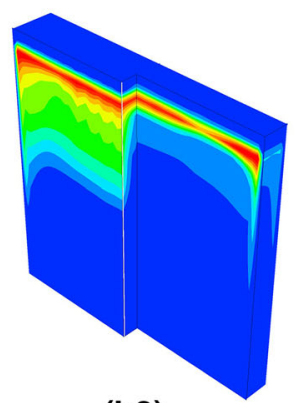

(b2)

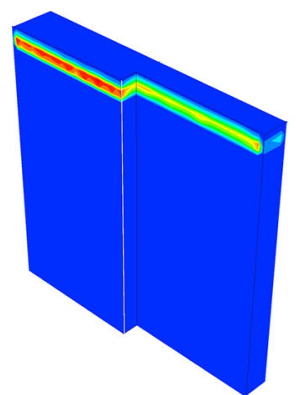

(c2)

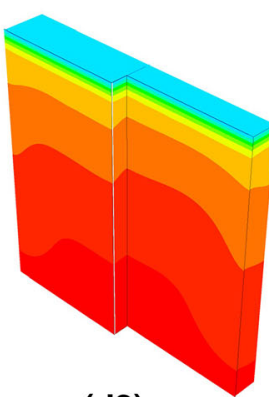

(d2)

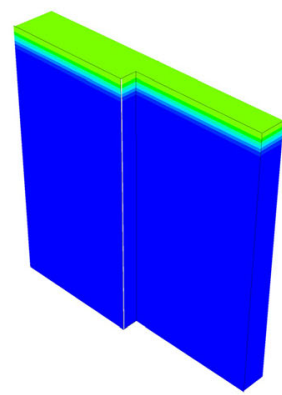

(e2)

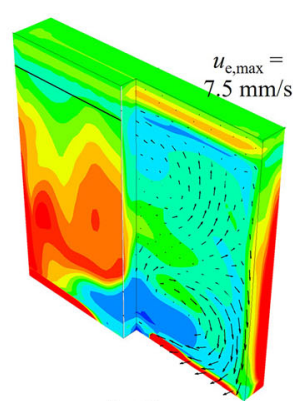

(a3)

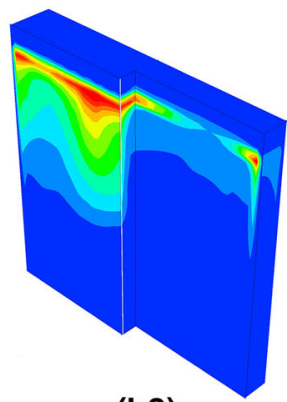

(b3)

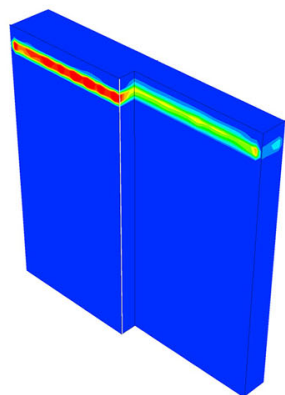

(c3)

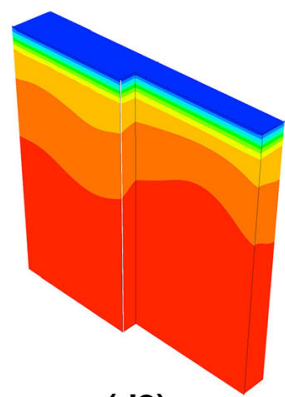

(d3)

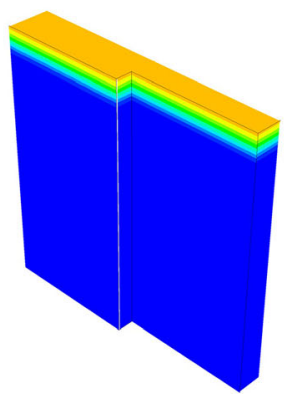

(e3) 
Fig. 9-Three-dimensional modeling results for Setup 2 (with crystal sedimentation) of (a) $f_{\mathrm{e}},(b) M_{\ell \mathrm{e}},(c) \dot{N}_{\mathrm{V}},(d) T$, and (e) $c_{\ell}$ (top to bottom) at 1) $t=80 \mathrm{~s}, 2) t=100 \mathrm{~s}$, and 3) $t=120 \mathrm{~s}$ (left to right). The results in the 1 st row are overlaid with $\vec{u}$ vectors (black arrows on the right-side plane) and the columnar tip front (black line on the left side plane).

fraction. The black lines are also displayed to identify the fronts of both structures, which correspond to the final CET.

The inset in Figure 11(a) illustrates the results for a cooling rate that is ten times larger than the reference case displayed in Figure 11(a). It can be observed that the growth of both solid structures is accelerated, and CET occurs sooner. As a result, instead of taking approximately $1100 \mathrm{~s}$ to reach the CET, under the increased cooling rate conditions, the CET occurs at 500 $\mathrm{s}$ at a dimensionless height of 0.11 . This outcome for different cooling rates agrees with the qualitative evidence reported by Gao and Wang ${ }^{[22]}$ on their experimental investigation of the effects of grain transport on the CET in dendritic alloy solidification with an aqueous

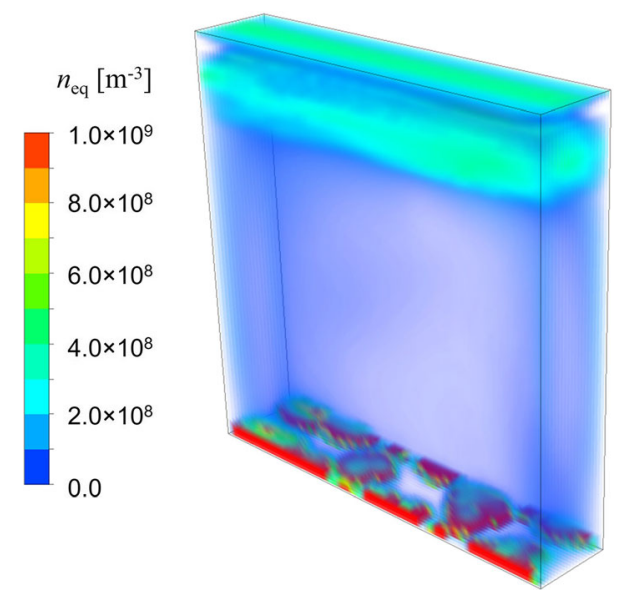

Fig. $10-$ Volume rendering of $n_{\mathrm{eq}}$ at $t=350 \mathrm{~s}$ for Setup 2. The transparency of the color legend changes linearly from completely opaque at $n_{\mathrm{eq}}=1 \times 10^{9}$ to $80 \%$ transparent at $n_{\mathrm{eq}}=0$. ammonium chloride solution. Despite not shown here, it was also found that a smaller packing limit promotes a faster CET and increases the height of the packed bed when CET is attained. As $f_{\mathrm{e}}$ reaches the packing limit, the crystals stop moving and form a rigid structure. With a smaller packing limit, the as-packed equiaxed structure is less compact and, thus, piles up faster as new crystal sediments.

\section{DISCUSSION}

Capillary-driven fragmentation is well understood as a mechanism for dendrite coarsening. ${ }^{[10,15]}$ In addition, the fragments produced by this mechanism can act as a source of equiaxed crystals and lead to CET if they are transported out of the mushy zone by the flow or by crystal sedimentation. ${ }^{[1]}$ This paper presents a first attempt to bridge the capillary-driven fragmentation with grain transport phenomenon in a mixed columnar-equiaxed solidification model.

To evaluate the model, test simulations and comparisons with the most recent publications were conducted. For example, the calculated results of $S_{\mathrm{V}}$ (the key parameter for estimating the fragmentation rate), as achieved under pure diffusive solidification conditions (no flow) were validated against the phase-field simulation of the NEB model ${ }^{[15]}$ (Figure 4), and a generally good agreement was obtained. Furthermore, even though the equation for $N_{\mathrm{V}}$, originally proposed by Cool and Voorhees ${ }^{[10]}$ under isothermal conditions, is extended with a minor modification to non-isothermal conditions, its outcome still agrees with the experimental measurements of the authors. The modified formulation for $N_{\mathrm{V}}$ seems to describe better the fragmentation event in the solidification-dominant stage and is consistent with experimental studies on fragmentation evolution ${ }^{[19]}$ without losing its validity in the coarsening-dominant stage (Figure 5).

By coupling fragmentation and multiphase transport phenomena in the solidification model, a practical computational fluid dynamics tool was developed to calculate the as-cast structure with CET. For Setup 2, a CET was predicted. The fragments that are created from

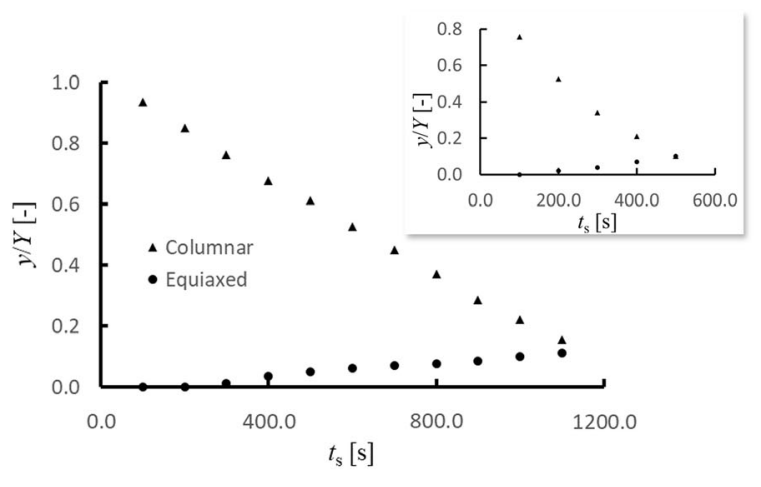

(a)

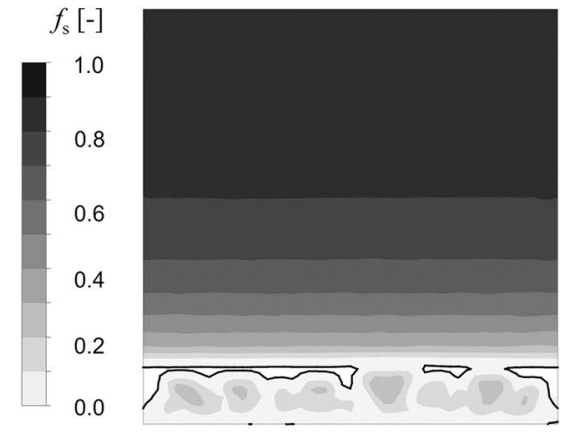

(b)

Fig. 11-(a) Evolution of the columnar dendritic front and that of the equiaxed packing bed and $(b)$ distribution of solid phase volume fraction $f_{\mathrm{s}}\left(=f_{\mathrm{c}}+f_{\mathrm{e}}\right)$ at $t=1100 \mathrm{~s}$. The inset in (a) represents the simulation results obtained with a cooling rate of $1.2 \mathrm{~K} / \mathrm{s}$. 


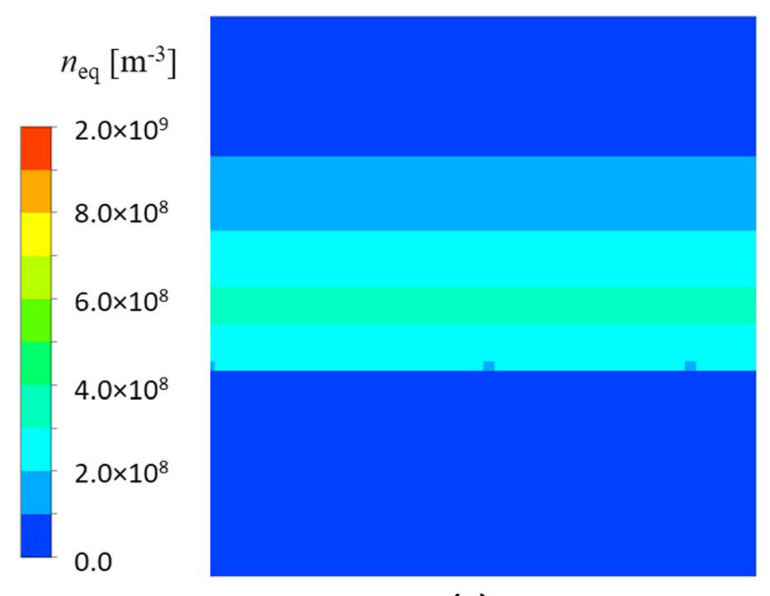

(a)

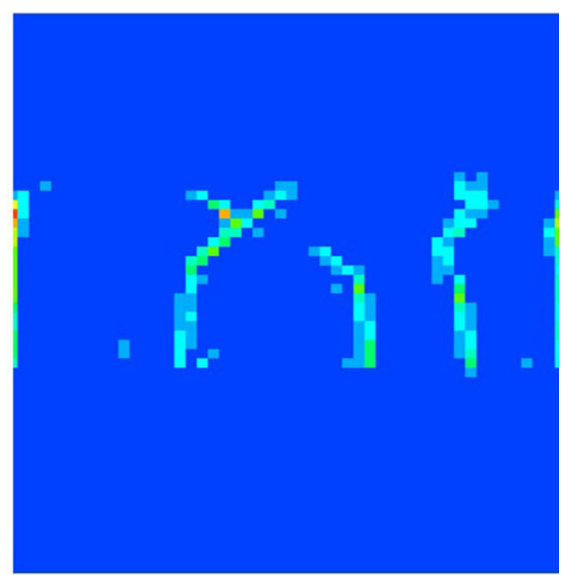

(b)

Fig. 12-Modeling results for Setup 2 (without solid motion) of $n_{\mathrm{eq}}$ for $(a)$ the current work and $(b)$ previous fragmentation formulation ${ }^{[25,26]}$ with a fitting constant of $1 \times 10^{-4}$ at $t=800 \mathrm{~s}$.

the upper columnar mushy region can settle down, pile up from the bottom of the casting domain, and finally block the columnar front. The qualitative analysis of the sequence of events is in line with the observations reported in experimental papers available in the literature $\left(e . g .,^{[22]}\right)$. In principle, the model is suitable for predicting the grain-evolutionary cycle in castings, as described by Hellawell et al. ${ }^{[1]}$ : (1) fragmentation of dendritic arms, (2) transport of fragments through the mushy zone into the bulk melt by the flow, (3) survival of as-transported fragments through the superheat, (4) growth and sedimentation of fragments in the bulk melt, and (5) interaction with the columnar structure, leading to CET.

It is important to mention that the newly formed fragments are assumed to be transported out of the mushy zone only when the columnar solid fraction ranges between 0.1 and 0.2 . The lower limit represents the onset of fragmentation and has been chosen based on the assumption that below this value, the columnar structure has not developed enough higher-order arms that are prone to fragmentation. The higher limit was already employed in other studies (e.g., $\left.{ }^{[31]}\right)$ and determines an arbitrary columnar solid fraction at which the fragments are prevented from being transported out of the mushy zone because of the reduction in the interdendritic space. In this case, once a fragment detaches from the columnar structure, it remains inside the mushy zone and is not considered for CET. Despite the relatively small window for fragments to be transported out of the mushy zone, many fragments can still be found piling up at the bottom of the domain in Setup 2.

A simple fragmentation formulation, as inspired by the earlier work of Campanella et al., ${ }^{[24]}$ was also proposed by the current authors. ${ }^{[25,26]}$ For fragmentation, the approach required the transport of the solute-enriched melt through the interdendritic flow in the columnar growth direction, and a fitting coefficient $(\gamma)$ was assigned to encompass all unknown contributing factors to the fragmentation mechanisms. This includes the curvature effect of the dendrites, latent heat-induced thermal fluctuation, and solute diffusion in the interdendritic melt. The value of the coefficient was determined by fitting the simulation results to the experimental measurements, for several different conditions.

This simple approach was an attractive option with the knowledge available at that time. Since then, new studies on capillary-driven fragmentation that provide relevant information on the matter $($ e.g., $[9,10,15])$ have been published. The current fragmentation model relies on this new state-of-the-art capillary-driven fragmentation theory. Contrary to the previous approach, where the melt flow was required to be parallel to the columnar growth direction to trigger the fragmentation event, in the present work, fragmentation can occur under isothermal conditions, with any flow direction, as well as in the absence of flow. Furthermore, a no case-dependent fitting coefficient $(\gamma)$ is required. Figure 12 highlights the qualitative differences between the results obtained with the two different approaches for Setup 2 without solid motion at $t=800 \mathrm{~s}$. Even though the maximum fragmentation rate occurs near the tip front in both cases and the number of fragments can be made similar by adjusting the fitting coefficient in the previous approach, the fragmentation occurrence distributions are very different. This is because the interdendritic flow is nonuniform, which leads to an intermittent and nonuniform fragmentation pattern in the previous approach. This contrasts with the continuous fragmentation pattern behind the columnar tip front in the capillary-driven fragmentation formulation.

The fragmentation process is a complex mechanism that is not fully understood yet, and new modeling approaches are important for improving the knowledge regarding the physics involved. Nevertheless, to fully understand the mechanisms underlying the dynamics of fragmentation and validate the simulation results, further experimental studies under non-isothermal conditions and using objective measurement data are necessary. In particular, further research is required to 
extend Cool and Voorhees' equation for the fragmentation rate from the coarsening-dominant stage to the entire solidification spectrum. In addition, further experiments must be conducted to determine the solid fraction window within which the fragments can be transported out of the mushy zone, the initial (average) size of fragments, as well as the alloy-dependent constants used in Eq. [1] for a wider range of alloys.

\section{CONCLUSIONS}

Capillary-driven fragmentation and grain transport were bridged and implemented in a mixed columnar-equiaxed solidification model. The fragmentation model was validated against the results by Neumann-Heyme et al. ${ }^{[15]}$ and extended to non-isothermal conditions by modifying the original equation for the number of fragments proposed by Cool and Voorhees ${ }^{[10]}$. Reasonable results were also obtained when liquid flow and fragment sedimentation were considered, which suggests that the current mixed columnar-equiaxed solidification model can be an important tool for industrial casting applications, specifically for the detection of CET. Nevertheless, further validation, which requires new experimental works that provide objective data on the fragmentation evolution to be used in computational simulations, needs to be performed.

\section{ACKNOWLEDGMENTS}

This work was supported by the FWF Austrian Science Fund in the framework of the FWF-NKFIN joint project (FWF, I4278-N36).

\section{CONFLICT OF INTEREST}

On behalf of all authors, the corresponding author states that there is no conflict of interest.

\section{FUNDING}

Open access funding provided by Montanuniversität Leoben.

\section{OPEN ACCESS}

This article is licensed under a Creative Commons Attribution 4.0 International License, which permits use, sharing, adaptation, distribution and reproduction in any medium or format, as long as you give appropriate credit to the original author(s) and the source, provide a link to the Creative Commons licence, and indicate if changes were made. The images or other third party material in this article are included in the article's Creative Commons licence, unless indicated otherwise in a credit line to the material. If material is not included in the article's Creative Commons licence and your intended use is not permitted by statutory regulation or exceeds the permitted use, you will need to obtain permission directly from the copyright holder. To view a copy of this licence, visit http://creat ivecommons.org/licenses/by/4.0/.

\section{REFERENCES}

1. S. Hellawell, S. Liu, and S.Z. Lu: JOM, 1997, vol. 49, pp. 18-20.

2. B. Chalmers and R.B. Williamson: Science, 1965, vol. 148, pp. $1717-18$

3. K.A. Jackson and J.D. Hunt: Trans. Metall. Soc. AIME, 1966, vol. 236, pp. 1129-42

4. D.M. Herlach, K. Eckler, A. Karma, and M. Schwarz: Mater. Sci. Eng. A, 2001, vols. 304-306, pp. 20-25.

5. H. Yasuda, K. Morishita, N. Nakatsuka, T. Nishimura, M. Yoshiya, A. Sugiyama, K. Uesugi, and A. Takeuchi: Nat. Commun., 2019, vol. 10, pp. 1-5.

6. M.C. Flemings: Mater. Trans., 2005, vol. 46, pp. 895-900.

7. H. Neumann-Heyme, K. Eckert, and C. Beckermann: Phys. Rev. E, 2015, vol. 92, pp. 1-5.

8. S.C. Huang and M.E. Glicksman: Acta Metall., 1981, vol. 29, pp. 717-34.

9. T. Cool and P.W. Voorhees: Philos. Trans. R Soc. A Math. Phys. Eng. Sci., 2018, vol. 376, pp. 1-15.

10. T. Cool and P.W. Voorhees: Acta Mater., 2017, vol. 127, pp. 359-67.

11. S.P. Marsh and M.E. Glicksman: Metall. Mater. Trans. A Phys. Metall. Mater. Sci., 1996, vol. 27, pp. 557-67.

12. S. Steinbach and L. Ratke: Mater. Sci. Eng. A., 2005, vols. 413-415, pp. 200-204.

13. S. Steinbach, L. Ratke, G. Zimmermann, L. Sturz, A. Roósz, J. Kovács, Y. Fautrelle, O. Budenkova, J. Lacaze, S. Dost, G.-U Grün, N. Warnken, and M. Wu: Proc. 5th Decenn. Int. Conf. Solidif. Process., Old Windsor, 2017, pp. 267-271.

14. H. Zhang, M. Wu, C.M.G. Rodrigues, A. Ludwig, and A. Kharicha: Metall. Mater. Trans. A, 2021, vol. 52, pp. 3008-22.

15. H. Neumann-Heyme, K. Eckert, and C. Beckermann: Acta Mater., 2017, vol. 140, pp. 87-96.

16. J. Pilling and A. Hellawell: Metall. Mater. Trans. A Phys. Metall. Mater. Sci., 1996, vol. 27A, pp. 229-32.

17. D. Ruvalcaba, R.H. Mathiesen, D.G. Eskin, L. Arnberg, and L. Katgerman: Acta Mater., 2007, vol. 55, pp. 4287-92.

18. R.H. Mathiesen, L. Arnberg, P. Bleuet, and A. Somogyi: Metall. Mater. Trans. A Phys. Metall. Mater. Sci., 2006, vol. 37, pp. $2515-24$

19. E. Liotti, A. Lui, S. Kumar, Z. Guo, C. Bi, T. Connolley, and P.S. Grant: Acta Mater., 2016, vol. 121, pp. 384-95.

20. CJ. Paradies, R.N. Smith, and M.E. Glicksman: Metall. Mater. Trans. A Phys. Metall. Mater. Sci., 1997, vol. 28, pp. 875-83.

21. Q. Han and A. Hellawell: Metall. Mater. Trans. B Process Metall. Mater. Process. Sci., 1997, vol. 28, pp. 169-73.

22. J.W. Gao and C.Y. Wang: J. Heat Transfer., 1999, vol. 121, pp. $430-37$.

23. M.C. Flemings and G.E. Nereo: Trans. Metall. Soc. AIME, 1967, vol. 239 , pp. 1449-62.

24. T. Campanella, C. Charbon, and M. Rappaz: Metall. Mater. Trans. A, 2004, vol. 35, pp. 3201-10.

25. Y. Zheng, M. Wu, A. Kharicha, and A. Ludwig: Modell. Simul Mater. Sci. Eng., 2018, vol. 26, p. 015004.

26. Y. Zheng, M. Wu, A. Kharicha, and A. Ludwig: Comp. Mater. Sci., 2016, vol. 24, pp. 456-70.

27. W. Montgomery and F. Incropera: Exp. Heat Transfer, 1998, vol. 11, pp. 59-86.

28. E. Liotti, A. Lui, R. Vincent, S. Kumar, Z. Guo, T. Connolley, IP. Dolbnya, M. Hart, L. Arnberg, R.H. Mathiesen, and P.S. Grant: Acta Mater., 2014, vol. 70, pp. 228-39.

29. E. Lesoult: Mater. Sci. Eng. A, 2005, vols. 413-414, pp. 19-29. 
30. N. Leriche, H. Combeau, C.-A. Gandin, and M. Založnik: $I O P$ Conf. Ser. Mate. Sci. Eng., 2015, vol. 84, p. 012087.

31. M. Wu and A. Ludwig: Metall. Mater. Trans. A, 2007, vol. 38, pp. $1465-75$.

32. M. Wu and A. Ludwig: Metall. Mater. Trans. A, 2006, vol. 37, pp. 1613-31.

33. J. Lipton, M.E. Glicksman, and W. Kurz: Mater. Sci. Eng., 1984, vol. 65 , pp. 57-63.

34. Q. Li and C. Beckermann: Phys. Rev. E, 1998, vol. 57, pp. $3176-88$.
35. K.P. Young and D.H. Kirkwood: Metall. Trans. A, 1975, vol. 6, pp. 197-205.

36. D.G. McCartney and J.D. Hunt: Acta Metall., 1981, vol. 29, pp. $1851-63$

37. M. Gündüz and E. Çadirli: Mater. Sci. Eng. A, 2002, vol. 327, pp. 167-85.

Publisher's Note Springer Nature remains neutral with regard to jurisdictional claims in published maps and institutional affiliations. 